\title{
Impact of Secretory Immunoglobulin A Level on Dental Caries Experience in Asthmatic Children
}

\author{
Abla Arafa ${ }^{1}$, Salwa AlDahlawi ${ }^{2}$, Adel Hussien $^{3}$
}

\begin{abstract} saliva flow rate $(0.64 \pm 0.20)$. progression mainly of primary dentition.

Keywords: Asthma, Children, Dental caries, Saliva, Secretory immunoglobulin A.

International Journal of Clinical Pediatric Dentistry (2019): 10.5005/jp-journals-10005-1663
\end{abstract}

Objectives: To assess the association between different factors in saliva and dental caries experience in children with bronchial asthma. Materials and methods: A total of 60 asthmatic children and 60 healthy controls of both genders with age ranging from 4- to 12-year-old. The asthmatics were grouped according to disease severity into mild, moderate, or severe asthma. All the children were clinically examined to assess their dental caries experience (deft/DMFT), and stimulated saliva samples were collected to measure the saliva pH, flow rate, á-amylase, and secretory immunoglobulin A (slgA)-level changes. The data were statistically analyzed using the SPSS program (v. 23) to test for significance at $p \leq 0.05$.

Results: Asthmatic children presented significantly higher deft mean value $(6.77 \pm 1.69)$, as well as significantly reduced stimulated saliva flow $(0.82 \pm 0.2)$ and slgA $(29.42 \pm 6.31)$ when compared to healthy control. The slgA of asthmatics showed statistically significant negative correlation with deft and DMFT. Severe asthmatics presented significantly the lowest slgA mean level $(23.61 \pm 5.33)$ and the most reduced

Conclusion: The reduction in saliva flow rate and secretory immunoglobulin A render asthmatic children more prone to increased dental caries

\section{INTRODUCTION}

Bronchial asthma is one of the most common chronic diseases that affect variable individuals particularly children and characterized by repeated raids of chest wheeze and breathlessness owing to hyperresponsiveness and pathological narrowing of the respiratory air-passages. Chronic asthma accounts for one of the topmost 10 chronic-disability-adjusted life conditions in children. ${ }^{1}$ Several studies have demonstrated a considerable increase in the prevalence of wheeze and asthma in children. ${ }^{2,3}$ The Global Asthma Network reported increased asthma symptoms and severity particularly in low- to middle-income countries. ${ }^{4}$

Early manifestation of bronchial asthma at the first year of life can cause dento-facial changes. Therefore, the prompt diagnostic of the illness, as well as the establishment of a proper therapy could improve the symptoms and chronic complications of asthma and also reduce its adverse impact on craniofacial development. ${ }^{5}$

The relationship between persistent bronchial asthma and dental caries incidence has been studied widely but with controversy results. However, a recent meta-analysis investigation has reported that caries incidence found almost doubled in asthmatic subjects both for primary and permanent dentition compared to that of the healthy control. ${ }^{6}$

Restoring optimal pulmonary function and evasion of any side effect of the used drugs are the prime objectives of the anti-asthma medication to achieve healthy active individual. Asthma severity determine, to a great extent, the type and frequency of anti-asthma drugs. Recent guidelines for management of bronchial asthma encourage the utilization of anti-inflammatory (corticosteroids and non-steroidal drugs) as well as bronchodilator inhaler for the prophylaxis of persistent asthma and management of acute attacks exacerbation.7 A possible association was postulated between increased dental caries incidence and bronchial asthma particularly
${ }^{1}$ Department of Pediatric Dentistry and Dental Public Health, Faculty of Oral and Dental Medicine, Misr International University, Cairo, Egypt; Department of Preventive Dentistry, College of Dentistry, Umm Al-Qura University, Mecca, Kingdom of Saudi Arabia

${ }^{2}$ Department of Basic Medical Sciences, College of Dentistry, Umm AlQura University, Mecca, Kingdom of Saudi Arabia

${ }^{3}$ Department of Preventive Dentistry, College of Dentistry, Umm AlQura University, Mecca, Kingdom of Saudi Arabia; Department of Pediatric Dentistry, Faculty of Dentistry, Al-Azhar University, Cairo, Egypt Corresponding Author: Abla Arafa, Department of Pediatric Dentistry and Dental Public Health, Faculty of Oral and Dental Medicine, Misr International University, Cairo, Egypt; Department of Preventive Dentistry, College of Dentistry, Umm Al-Qura University, Mecca, Kingdom of Saudi Arabia, Phone: +20 22954386, e-mail: ablaarafa@ hotmail.com

How to cite this article: Arafa A, AIDahlawi S, Hussien A, et al. Impact of Secretory Immunoglobulin A Level on Dental Caries Experience in Asthmatic Children. Int J Clin Pediatr Dent 2019;12(5):414-418.

Source of support: King Abdulaziz City for Science and Technology (KACST)

Conflict of interest: None

in children either directly via biological pathways or indirectly under the effect of used anti-asthma medicament, which could leave its negative effect mainly on saliva secretion and composition. ${ }^{8}$

Multiple factors in the bio-fluid of saliva found to play an important biological defensive mechanism against dental caries. ${ }^{9}$ The secretory immunoglobulin $\mathrm{A}(\mathrm{s} \lg \mathrm{A})$ presents the most abundant immunoglobulin in human saliva, which imbed microbial adherence to the tooth structure, reduces bacterial aggregation, and antagonizes bacterial toxins and enzymes. Furthermore, salivary á-amylase was also suggested to be able to 
govern the process of dental plaque formation and further microbial adhesion. Low levels of salivary á-amylase claimed to encourage dental caries progression particularly, in susceptible children. ${ }^{10}$ Salivary immunoglobulins and enzymes' secretion is controlled by $\beta$-adrenergic receptors where chronic stimulation, as with $\beta$-agonist antiasthmatic drugs, proposed to be associated with not only reduction but also alteration in salivary proteins' secretion. ${ }^{11}$ Another important mechanism to guard against initiation and progression of dental caries is the preservation of relatively neutral saliva $\mathrm{pH}$ via different buffering systems. Alteration in the former mentioned balance, as expected to accompany the use of antiasthma medications, would imbed one of the innate oral defences against oral and dental diseases. ${ }^{12}$ In addition, the salivary flow not only provides washing effect that cleans oral and dental surfaces but also nourish the oral environment with variant elements necessary to create adequate protection against dental caries. Asthmatic patients frequently report decreased saliva secretions and concomitant oral complications. ${ }^{13}$

Scanty studies focused on the correlation between salivary characteristics of asthmatics and oral manifestations particularly in asthmatic children. ${ }^{6,14}$ Understanding the impact of bronchial asthma on dental health would aid to provide comprehensive dental management and early interprofessional consultation. Therefore, this study was conducted to assess the dental caries experience of children suffering from bronchial asthma and the possible association between different salivary factors and the extent of dental caries in asthmatic children. The null hypotheses tested that no association could be found between changes in saliva of children suffering from bronchial asthma and increased risk of dental caries.

\section{Materials and Methods}

\section{Study Design}

A total of 120 participants aged from 4- to 12-year-old were enrolled in the present study during the period from September 2016 to January 2017. The sample consisted of 60 children ( 29 females and 31 males) formerly diagnosed with chronic asthma but no other systemic illness other than the asthma condition and 60 healthy children as a study control. Asthmatic children were recruited from the outpatients' clinic of Makkah Maternity and Children Hospital. Participants with persistent chronic asthma were further subdivided into mild, moderate and severe asthmatics $(n=20)$ by pediatric specialist according to severity of symptoms, acute exacerbation and frequent nocturnal symptoms. ${ }^{15}$ The ethical approval to conduct this study was obtained from the institutional review board UQU DENT-IRB and informed consent was collected from each caregiver before including the children into the study.

\section{Dental Examination}

Through dental examination of each participant was conducted to evaluate the oral health condition while sitting on an ordinary chair using sterile disposable diagnostic tools by the same examiner. The dental caries experience was assessed according to "WHO recommendations $2013^{\prime \prime} .^{16}$ For every child, the deft/DMFT indices were calculated separately, where (d/D) carious tooth, (e/M) indicated for extraction or missing tooth due to caries and (f/F) filling due to caries in primary or permanent teeth, respectively.

\section{Stimulated Salivary Flow Rate}

Following the dental examination, stimulated saliva was collected 2 hours after breakfast from 9- to 10-AM to reduce the effect of circadian variation. ${ }^{17}$ The children were asked to set in an upright position with the head bowed partly forward. About $1 \mathrm{~g}$ paraffin wax was given for each child to chew on it for 1 minute then asked to frequently deposit the collected saliva into graduated plastic container. After 5 minutes, the volume of the collected saliva was measured and divided by time to estimate the salivary flow rate per individual ( $\mathrm{mL} /$ minute).

\section{Saliva pH Measurement}

The saliva samples were immediately analyzed following their collection to evaluate the corresponding $\mathrm{pH}$ using digital salivary $\mathrm{pH}$ meter (Adwa instruments Kft, Szeged, Hungary). According to the manufacturer instructions, one $\mathrm{mL}$ of saliva was dispensed on $\mathrm{pH}$-sensitive electrode and the reading left few seconds for stabilization then recorded per sample. Following each reading, gauze moistened with distilled water was used to clean the $\mathrm{pH}$-electrode, which then was immersed in standard solution of $\mathrm{pH} 7$ to be ready for the next reading.

\section{Salivary IgA and a-Amylase Determination}

The saliva samples were centrifuged at 3,000 rpm for 15 minutes then the saturate was stored at $-70^{\circ} \mathrm{C}$ till analysis. The concentration of slgA ( $\mu \mathrm{g} / \mathrm{mL})$ was measured using DRG ${ }^{\circledR}$ ELISA kit for slgA (DRG International Inc., USA) and the salivary á-amylase $(\mathrm{U} / \mathrm{mL})$ was measured using DRG ${ }^{\circledR}$ ELISA kit for á-amylase (DRG International Inc., USA) following the manufacturer's directions.

\section{Statistical Analysis}

The collected data were statistically analyzed using SPSS v.23 program to check for significance at $p \leq 0.05$. Student's $t$ test was used to search significance between asthmatics and the healthy control group regarding the effect of different saliva variables. The impact of the asthma condition severity on different variables (deft/DMFT, saliva flow, saliva $\mathrm{pH}$, slgA and a-amylase mean values) was examined using one-way ANOVA test followed by multiple comparisons Tukey's post hoc test.

\section{Results}

The age mean and SD were $7.38 \pm 2.83$ and $8.38 \pm 3.03$ for the control and asthmatic groups, respectively $(p>0.05)$. The results of the study are presented in Tables 1 and 2 . The deft mean scores of the asthmatics presented statistically significant higher mean values compared to that of the healthy controls ( $p \leq 0.05$ ). On the other hand, the flow rate and slgA level showed statistically significant lower mean values in contrast to the control group

Table 1: Different variables among asthmatics and control groups ( $n=60$ per group)

\begin{tabular}{llll}
\hline Variable & & Control & Asthmatics \\
\hline Gender & Female & $27(23 \%)^{\mathrm{a}}$ & $29(24 \%)^{\mathrm{a}}$ \\
& Male & $33(28 \%)^{\mathrm{a}}$ & $31(26 \%)^{\mathrm{a}}$ \\
Age & & $7.38 \pm 2.83^{\mathrm{a}}$ & $8.38 \pm 3.03^{\mathrm{a}}$ \\
Deft & $4.02 \pm 2.49^{\mathrm{a}}$ & $6.77 \pm 1.69^{\mathrm{b}}$ \\
DMFT & $1.88 \pm 1.18^{\mathrm{a}}$ & $2.34 \pm 1.23^{\mathrm{a}}$ \\
Flow rate $(\mathrm{mL} /$ minute $)$ & $1.75 \pm 0.63^{\mathrm{a}}$ & $0.84 \pm 0.20^{\mathrm{b}}$ \\
$\mathrm{pH}$ & $6.41 \pm 2.43^{\mathrm{a}}$ & $6.03 \pm 1.58^{\mathrm{a}}$ \\
slgA $(\mu \mathrm{g} / \mathrm{mL})$ & $83.04 \pm 6.42^{\mathrm{a}}$ & $29.42 \pm 6.31^{\mathrm{b}}$ \\
á-Amylase $(\mathrm{U} / \mathrm{mL})$ & $79.59 \pm 7.03^{\mathrm{a}}$ & $80.75 \pm 6.76^{\mathrm{a}}$ \\
\hline
\end{tabular}

Different lower case alphabets in superscript in the same row indicate significance 
Impact of Secretory Immunoglobulin A Level on Dental Caries Experience in Asthmatic Children

Table 2: Different variables among mild, moderate and severe asthmatics

\begin{tabular}{|c|c|c|c|c|}
\hline Variable & & Mild & Moderate & Severe \\
\hline \multirow[t]{2}{*}{ Gender } & Female & $12(20 \%)^{a}$ & $11(18 \%)^{a}$ & $6(10 \%)^{a}$ \\
\hline & Male & $8(13 \%)^{a}$ & $9(15 \%)^{a}$ & $14(23 \%)^{a}$ \\
\hline Age & & $7.88 \pm 2.21^{\mathrm{a}}$ & $8.46 \pm 1.98^{\mathrm{a}}$ & $8.74 \pm 2.09^{a}$ \\
\hline Deft & & $5.75 \pm 1.48^{\mathrm{a}}$ & $6.40 \pm 1.67^{a}$ & $8.15 \pm 0.81^{a}$ \\
\hline DMFT & & $2.40 \pm 1.72^{\mathrm{a}}$ & $2.10 \pm 1.02^{\mathrm{a}}$ & $2.55 \pm 1.39^{a}$ \\
\hline Flow rate ( $\mathrm{mL} /$ minute) & & $1.05 \pm 0.09^{a}$ & $0.84 \pm 0.20^{b}$ & $0.64 \pm 0.20^{c}$ \\
\hline $\mathrm{pH}$ & & $6.39 \pm 2.11^{a}$ & $6.18 \pm 1.37^{a}$ & $5.52 \pm 1.74^{\mathrm{a}}$ \\
\hline $\operatorname{slg} A(\mu \mathrm{g} / \mathrm{mL})$ & & $33.13 \pm 5.13^{a}$ & $31.53 \pm 5.18^{a}$ & $23.61 \pm 5.33^{b}$ \\
\hline á-Amylase $(\mathrm{U} / \mathrm{mL})$ & & $76.65 \pm 6.81^{a}$ & $80.15 \pm 8.23^{a}$ & $82.78 \pm 8.69^{a}$ \\
\hline
\end{tabular}

Different lower case alphabets in superscript in the same row indicate significance

( $p \leq 0.05)$. Severe asthmatics presented significantly the least mean value of saliva flow rate and slgA compared to that of mild and moderate asthmatics ( $p \leq 0.05)$. The slgA of asthmatic children yielded statistically significant negative correlation with deft and DMFT ( $p \leq 0.05)$. Both saliva $\mathrm{pH}$ nd salivary a-amylase values showed statistically in-significant difference between the test groups $(p>0.05)$.

\section{Discussion}

Many speculations were suggested as the possible senses behind dental caries experience in asthmatic patients; however, scanty studies focused on the associative factors in asthmatics and children in particular. The results of the present study reject the null hypothesis and disclose that certain changes in the saliva of children suffering from bronchial asthma found to be resposible for the increased risk of dental caries.

Despite different indeces developed for dental caries assessment, the WHO recognized the deft and the DMFT indeces as strong reliable and repreducable mean of dental caries detection and further comparison between groups. ${ }^{18}$ Assessment of stimulated salivary flow rate is considered a highly reliable technique in systemic diseases and conditions expected to be associated with a degree of reduced flow or affected saliva secreation. ${ }^{19}$ The use of $\mathrm{pH}$ meter as a quantitative measure of saliva buffer capacity, found to be able to reduce the inherited subjective deviation of the colourimetric systems, accordingly, considered as a valid mean in accurate determination of salivary. ${ }^{20}$

The results of this study revealed significant increase in dental caries experience of asthmatic children where with the increase in severity of asthma condition, a higher dental caries would be experienced by the asthmatics particularly the primary dentition without significant adverse effect as the children mature. ${ }^{7}$ Similar findings were reported by other researchers that children with bronchial asthma found to be at higher risk for increased dental caries. ${ }^{21}$ The results of a study by Stensson et al. also indicated that preschool children with asthma have a higher prevalence of caries than children without asthma. ${ }^{23}$ Reddy et al. added also that with the increase in asthma severity, there is increase in dental caries affection. ${ }^{24}$ It was also reported that asthma condition would double the risk for dental caries. ${ }^{25}$ The increase in caries experience of asthmatics could be attributed to number of reasons. The condition itself and the anti-asthmatic medicament frequently claimed to be of prime association with elevated dental caries record. ${ }^{11,22}$ The $\beta 2$-agonists bronchodilator used to relieve asthma symptoms either in syrup or dry-powder inhaler form were highly linked to higher caries susceptability of asthmatics particularly to manage the nocturnal asthma symptoms in children.,24,26 Either directly through being sugar added or indirectly via the adverse effect of beta 2 agonist anti-asthmatics in reducing the salivary flow rate and composition. ${ }^{27}$

Multiple factors in the saliva of the asthmatics presented possible association with increased dental caries. Similar to the finding of the present study, the saliva flow rate of asthmatic children reported significant reduction. The normal average of salivary flow rate estimated to range from $1.5-1.8 \mathrm{~mL} /$ minute. ${ }^{28}$ Ultered flow rate found to develop due to the oral breathing habit accompany asthmatic condition in trial to increase air ingress particularly during attacks or in case of nasal obstruction. Furthermore, this impairment of the saliva secretion rate and composition could possibly result from the down-regulation of $\beta$-receptors caused by beta 2 agonist treatment as well as the frequent use of anti-histaminic drugs. ${ }^{29}$ The net dimish of the salivary flow of asthmatic children would prohibit the protective effect of saliva against dental caries. ${ }^{30}$ The reduction in saliva flow would not only affect the bioavailability of calcium and phosphrous ions necessary for remineralizing affected surfaces, but also debrive the oral environment from the saliva mechanical washing effect and thrust asthmatic patient for increased fluid consumption, sugar-sweetened beverage in particular. ${ }^{29,31}$

In addition, the results of this study presented significant decrease in slgA mean level of the asthmatic children that affected by asthma severity with further significant negative correlation with deft and DMFT mean score. Ultered saliva composition mainly interm of significant decrease in the slgA mean level, observed to be acompained with subsequent affection of the immune response and increased dental caries progression. ${ }^{32}$ The slgA dominates immunoglobulins secreated into the saliva thus accounted for the major role of defence against bacterial adhesion and dental plaque formation. It has been suggested that the content of slgA could be considered as genetic or environmental determinant factor predesposing to dental caries andbronchial asthma as well as posses leading function in the immune system. ${ }^{6}$ Furthermore, other researchers reported that the use of corticosteroids as anti-asthmatic inhalers found to be able to reduce the total content of $\operatorname{sigA} .{ }^{33,34}$

Former studies postulated a possible association between salivary á-amylase and increased dental caries acivity as a result of its ability to hydrolyze dietry starch providing more glucose within the plaque matrix in proximity to the tooth surface. ${ }^{10,35}$ However, the present study observed insignificant difference compared to the control group. This could be attributed to the difference in 
the age range of the study sample and the extent of affected flow as well as saliva composition in asthmatic children. Furthermore, multiple saliva constituents and immunologic factors could be related to oral microbs growth and multiplication where certain components as slgA and IgG showed augmenting or antagonizing impact on a-amylase mechanism of action, thus enhances or undermind the association between salivary a-amylase and dental caries activity. ${ }^{35}$

Although salivary $\mathrm{pH}$ plays critical role in development and progression of dental caries in asthmatic children, ${ }^{36}$ our findings couldn't reveal significant reduction in the salivary $\mathrm{pH}$. This could be attributed to to the variation in the degree of patients compliance with the theraputic regimen as well as the difference in the mode of saliva samples' collection and in the present study, the procedure was not attemped following the use of the antiasthmatic medicaments. ${ }^{37}$

\section{Conclusion}

It can be concluded that:

- Reduced salivary flow rate and the immunoglobulin A ( $\lg A)$ level showed strong association with increased dental caries experience in asthmatic children particularly in primary dentition.

- Severe asthma condition showed the most reduced saliva flow rate and the least slgA level.

\section{ACKnOWLedgment}

The authors acknowledge King Abdulaziz City for Science and Technology (KACST) for full sponsoring the research \# MS-35-148.

\section{References}

1. Asher I, Pearce N. Global burden of asthma among children. Int J Tuberc Lung Dis 2014;18(11):1269-1278. DOI: 10.5588/ijtld. 14.0170.

2. Venn A, Lewis $S$, et al. Increasing prevalence of wheeze and asthma in Nottingham primary schoolchildren. Eur Respir Dis 1998;11: 1324-1328. DOI: 10.1183/09031936.98.11061324.

3. Subbarao $P$, Mandhane $P$, et al. Asthma:epidemiology, etiology and risk factors. CMAJ 2009;181:E181-E190. DOI: 10.1503/cmaj.080612.

4. Ellwood P, Asher M, et al. The Global Asthma Network rationale and methods for Phase I global surveillance: prevalence, severity, management and risk factors. Eur Resp J 2017;49:1601-1605. DOI: 10.1183/13993003.01605-2016.

5. Tanaka L, Dezan C, et al. The influence of asthma onset and severity on malocclusion prevalence in children and adolescents. Dent Press J Orthod 2012;17:50e1-50e18. DOI: 10.1590/S2176-94512012000100007.

6. Alavaikko S, Jaakkola MS, et al. Asthma and caries: a systematic review and meta-analysis. Am J Epidemiol 2011;174:631-641. DOI: 10.1093/ aje/kwr129.

7. Shulman JD, Taylor SE, et al. The association between asthma and dental caries in children and adolescents: A population-based casecontrol study. Caries Res 2001;35(4):240-246. DOI: 10.1159/000047464.

8. Marx J, Preturius E. Asthma, a risk factor for dental caries. SADJ 2004;59:100-102.

9. Frenkel E, Ribbeck K. Salivary mucins in host defense and disease prevention. J Oral Microbiol 2015;7:29759. DOI: 10.3402/ jom.v7.29759.

10. Mojarad F, Fazlollahifar S, et al. Effect of alpha amylase on early childhood caries: a matched case-control study. Braz Dent Sci 2013;16:41-45. DOI: 10.14295/bds.2013.v16i1.873.
11. Maupome G, Shulman JD, et al. Is there a relationship between asthma and dental caries? a critical review of the literature. J Am Dent Assoc 2010;141:1061-1074. DOI: 10.14219/jada.archive.2010.0335.

12. Paganini M, Dezan CC, et al. Dental caries status and salivary properties of asthmatic children and adolescents. Int J Paediatr Dent 2011;21:185-191. DOI: 10.1111/j.1365-263X.2010.01109.x.

13. Del-Rio-Navarro BE, Corona-Hernandez L, et al. Effect of salmeterol and salmeterol plus beclomethasone on saliva flow and IgA in patients with moderate persistent chronic asthma. Ann Allergy Asthma Immunol 2001;87:420-423. DOI: 10.1016/S1081-1206(10)62925-0.

14. Ludviksson $B$, Arason $G$, et al. Allergic diseases and asthma in relation to serum immunoglobulins and salivary immunoglobulin $A$ in preschool children: a follow-up community-based study. Clin Exp Allergy 2005;35:64-69. DOI: 10.1111/j.1365-2222.2005.02141.x.

15. Koshak E. Classification of asthma according to revised 2006 GINA: Evolution from severity to control. Ann Thorac Med 2007;2:45-46. DOI: 10.4103/1817-1737.32228.

16. World Health Organization. Oral health surveys: basic methods, 5th ed., Switzerland: World Health Organization; 2013. pp. 42-47.

17. Leonor $S$, Laura $S$, et al. Stimulated saliva flow rate patterns in children: A six-year longitudinal study. Arch Oral Biol 2009;54:970-975. DOI: 10.1016/j.archoralbio.2009.07.007.

18. Baginska J, Rodakowska E, et al. Dental caries in primary and permanent molars in 7-8-year-old schoolchildren evaluated with Caries Assesment Spectrum and Treatment (CAST) index. BMC Oral Health 2014;14:74-82. DOI: 10.1186/1472-6831-14-74.

19. Navazesh M, Kumar S. Measuring salivary flow- challenges and oppertunities. JADA 2008;139:35S-40S. DOI: 10.14219/jada. archive.2008.0353.

20. Song CW, Kim HK, et al. Clinical usefulness of $\mathrm{pH}$ papers in the measurment of salivary pH. J Oral Med Pain 2015;40:124-129. DOI: 10.14476/jomp.2015.40.3.124.

21. Wierchola B, Emerich $\mathrm{K}$, et al. The association between bronchial asthma and dental caries in children of the developmental age. Eur J Paediatr Dent 2006;7:142-145. DOI: 10.1007/BF03262555.

22. Mazzoleni S, Stellini E, et al. Dental caries in children with asthma undergoing treatment with short-acting beta2-agonists. Eur J Paediatr Dent 2008;9:132-138.

23. Stensson $M$, Wendt LK, et al. Oral health in pre-school children with asthma-followed from 3 to 6 years. Int J Paediatr Dent 2010;20: 165-172. DOI: 10.1111/j.1365-263X.2010.01037.x.

24. Reedy DK, Hegde AM, et al. Dental caries status of children with bronchial asthma. J Clin Pediatr Dent 2003;27:293-296.

25. Matthews J. Asthma and dental caries. EBD 2012;13:41-48. DOI: 10.1038/sj.ebd.6400854.

26. Tanaka K, Miyake $Y$, et al. Dental caries and allergic disorders in Japanese children: the Ryukyus Child Health Study. J Asthma 2008;45(9):795-799. DOI: 10.1080/02770900802252119.

27. Vazquez $E$, Vazquez $F$, et al. Association between asthma and dental caries in the primary dentition of Mexican children. World J Pediatr 2011;7:344-349. DOI: 10.1007/s12519-011-0300-x.

28. Sanchez-Perez L, Irigoyen-Camacho E, et al. Stability of unstimulated and stimulated whole saliva flow rates in children. Int J Paediatric Dent 2016;26:346-350. DOI: 10.1111/ipd.12206.

29. Brigic A, Kobaslija $S$, et al. Cariogenic potential of inhaled antiasthmatic drugs. Med Arh 2015;69(4):247-250. DOI: 10.5455/ medarh.2015.69.247-250.

30. Kilinc G, Uzuner N, et al. Effect of dental care programme and fluoridation in the prevention of dental caries in asthmatic children. JPMA 2016;66:1378-1384.

31. Smith P, Masilamani M, et al. The false alarm hypothesis: Food allergy is associated with high dietary advanced glycation endproducts and proglycating dietary sugars that mimic alarmins. J Allergy Clin Immunol 2017;139:429-437. DOI: 10.1016/j.jaci.2016. 05.040 .

32. Kiykim A, Mumcu G, et al. Could Sublingual Immunotherapy Affect Oral Health in Childrenwith Asthma and/or Allergic Rhinitis Sensitized 
to House Dust Mite. Int Arch Allergy Immunol 2017;174:52-56. DOI: 10.1159/000480082.

33. Fukushima $C$, Matsuse $H$, et al. Salivary IgA and oral candidiasis in asthmatic patients treated with inhaled corticosteroid. J Asthma 2005;42(7):601-604. DOI: 10.1080/02770900500216259.

34. Krasteva A, Perenovska $P$, et al. Alteration in Salivary Components of Children with Allergic Asthma. Biotechnol Biotechnol Eq 2010;24(2):1866-1869. DOI: 10.2478/V10133-010-0050-2.
35. De Ferias $D$, Bezzera A. Salivary antibodies, amylase and protien from children with early childhood caries. Clin Oral Investig 2003;7:154-157. DOI: 10.1007/s00784-003-0222-7.

36. Thomas M, Parolia A, et al. Asthma and oral health:a review. Aust Dent J 2010;55:128-133. DOI: 10.1111/j.1834-7819.2010.01226.x.

37. Chellaih $P$, Sivadas $G$, et al. Effect of anti-asthmatic drugs on dental health: A comparative study. J Pharm Bioallied Sci 2016;8:S77-S80. DOI: $10.4103 / 0975-7406.171732$. 